\title{
A new beta titanium alloy system reinforced with superlattice intermetallic precipitates
}

\author{
Alexander J Knowles ${ }^{\mathrm{a}, \mathrm{b}, *}$, Tea-Sung Jun ${ }^{\mathrm{a}, \mathrm{c}}$, Ayan Bhowmik ${ }^{\mathrm{a}}$, Nicholas G Jones ${ }^{\mathrm{b}}$, T Ben Britton ${ }^{\mathrm{a}}$, Finn Giuliani ${ }^{\mathrm{a}}$, \\ Howard J Stone ${ }^{\mathrm{b}}$, David Dye \\ ${ }^{a}$ Department of Materials, Imperial College, South Kensington, London SW7 2AZ, UK \\ ${ }^{b}$ Department of Materials Sc ience and Metallurgy, University of Cambridge, Cambridge CB3 OF3, UK \\ ${ }^{c}$ Department of Mechanical Engineering, Incheon National University, 119 Academy-ro, Yeonsu-go, Incheon, 22012, South Korea
}

\begin{abstract}
Titanium alloys traditionally lack a nm-scale intermetallic precipitate that can be exploited for age-hardening from solid solution. Here such a strengthening concept is developed in the Ti-Fe-Mo system, with it being found that a high temperature $\beta$ (bcc A2) single-phase field for homogenisation can be obtained, which following ageing $\left(750{ }^{\circ} \mathrm{C}\right.$ $/ 80 \mathrm{~h}$ ) precipitated $\mathrm{B} 2 \mathrm{TiFe}<100 \mathrm{~nm}$ in size. The orientation relationship was found to be $<100>_{\mathrm{A} 2} / /<100>_{\mathrm{B} 2}$, $\{100\}_{\mathrm{A} 2} / /\{100\}_{\mathrm{B} 2}$, with a misfit of $-6.1 \%$. The alloy was found to be very hard $\left(\mathrm{HV}_{0.5}=6.4 \mathrm{GPa}\right)$ and strong $\left(\sigma_{\mathrm{y}, 0.2}=\right.$ $1.9 \mathrm{GPa}$ ) with a density of $6.68 \mathrm{~g} \mathrm{~cm}^{-3}$. TEM observation and micropillar deformation showed that the precipitates resist dislocation cutting.
\end{abstract}

Keywords: Titanium alloys, Precipitation, Microstructure, Mechanical properties, Dislocations

Nickel based superalloys that comprise an fcc (A1) structured matrix reinforced with fcc superlattice precipitates (i.e. $\mathrm{L}_{2}$ ) are famed for their combination of strength, plasticity and creep resistance over a wide temperature range $[1,2]$. The microstructure concept of a disordered matrix with an ordered superlattice precipitate has also been applied to bcc (A2) materials [3, 4]. For example, ferritic steels reinforced with $\mathrm{B} 2 \mathrm{NiAl}$ and/or $\mathrm{L}_{2} \mathrm{Ni}_{2} \mathrm{TiAl}$ precipitates have been found to have attractive creep performance $[5,6]$. The attempt to develop a similar strengthening concept in Ti-rich alloys has principally focused on the eutectic reaction between A2 Ti and B2 TiFe [7]. Developments of these alloys using ternary additions of Sn, Co [8] and $\mathrm{Nb}$ [9] have been successful at producing both higher strengths as well as increased ductility, which has been attributed to microstructural refinement.

An alternative microstructural production strategy to the eutectic reaction in the Ti-Fe binary system is the precipitation of B2 from within an A2 Ti matrix supersaturated with Fe, which may allow a nanoscale, rather than a microscale, microstructure to be produced. This would allow for precipitation strengthening at a more appropriate lengthscale, enabling ductilisation strategies to be developed. The precipitation strategy would also allow for hot forgeability in the single phase field and therefore grain refinement and low cost net shaping in thick sections. In the Ti-Fe binary system the solubility for $\mathrm{Fe}$ within A2 Ti is known to change markedly with temperature $[10,11]$. However, $\mathrm{Ti}$ alloys rich in $\mathrm{Fe}$ are prone

*Corresponding Author. a.knowles@ic.ac.uk to $\omega$ formation [12], which can embrittle the material [13]. Ternary additions of Mo, which is a potent $\beta$ stabilser [14], $>15$ at. $\%[13,15]$ were envisaged to reduce the prevalence of athermal $\omega$ and so improve ductility. Studies have been made on phase equilibria in the ternary Ti-Fe-Mo system [16-18], with recent work demonstrating that $\mathrm{A} 2+\mathrm{B} 2$ microstructures could be formed, which have high hardness, but also possessed an unavoidable micron scale intermetallic phase [19]. From the solvus position determined in previous studies $[19,20]$ a new alloy has been designed that can be solution heat treated within the A2 single-phase field and subsequently aged at a lower temperature to form B2 precipitates within the A2 Ti matrix. Here, the microstructure of this new alloy with composition Ti-17Fe-23Mo (at\%) is discussed and its mechanical behaviour examined.

A $40 \mathrm{~g}$ sample was prepared by arc melting of pure (> $99.9 \%$ ) elements under Ar (see Figure 1 in [21] for as-cast microstructure). Scanning electron microcopy (SEM) was performed on a Zeiss Auriga operated at $20 \mathrm{kV}$ equipped for energy-dispersive X-ray spectrometry (EDX) as well as having a Bruker electron backscatter diffraction (EBSD) detector with ARGUS ${ }^{\mathrm{TM}}$ forescattered electron (FSE) detectors. The bulk composition of the alloy was evaluated by averaging five $200 \times 400 \mu \mathrm{m}$ area measurements, at the top, bottom, centre and at either side of a section. It was found to be $(62.7 \pm 2.5) \mathrm{Ti}-(15.4 \pm 1.0) \mathrm{Fe}-(21.9 \pm 1.6) \mathrm{Mo}$ (at.\%), indicating a small amount of macrosegregation, whilst some casting porosity was also observed in the ingot.

After casting, the alloy's solidus was found to be $1180^{\circ} \mathrm{C}$ 
by differential scanning calorimetry (DSC) using a Netzsch 404 DSC. The alloy was solution heat treated in a quartz ampoule backfilled with $\mathrm{Ar}$ at $1170{ }^{\circ} \mathrm{C}$ for $16 \mathrm{~h}$ and then water quenched, after which second phases were not observed in the SEM (see Figure 1b in [21]). The alloy was then re-encapsulated and aged at $750{ }^{\circ} \mathrm{C}$ for $80 \mathrm{~h}$ and then water quenched. The density, determined by the Archimedes method, was $6.7 \mathrm{~g} \mathrm{~cm}^{-3}$. Grain sizes were determined by the linear intercept method [22] using FSE ARGUS $^{\mathrm{TM}}$ images, from the top to bottom of the bar. The average grain size was found to be $160 \pm 30 \mu \mathrm{m}$.

$\mathrm{X}$-ray diffraction (XRD) was performed to determine the phases present in the alloy and their lattice parameters using $\mathrm{Cu}_{K \alpha}$ radiation on flat samples $\sim 8 \mathrm{~mm}$ in diameter. Transmission electron microscopy (TEM) was performed using a JEOL 2100F microscope. TEM foils were prepared by mechanical thinning to $150 \mu \mathrm{m}$ followed by eletropolishing using 10 vol.\% perchloric acid in methanol at $-30{ }^{\circ} \mathrm{C}$ and $18 \mathrm{~V}$. Final thinning used a GATAN precision ion polishing system operated at $3 \mathrm{kV}$.

Microhardness indents using a $500 \mathrm{~g}$ load held for $10 \mathrm{~s}$ were made, averaging ten measurements. Macroscopic compression tests were performed on sub-sized $3 \mathrm{~mm}$ diameter, $5 \mathrm{~mm}$ high cylinders $[23,24]$. These were tested at a strain rate of $10^{-3} \mathrm{~s}^{-1}$ between $\mathrm{SiC}$ platterns lubricated with PTFE spray. Micropillars were prepared in a FEI Helios focused ion beam (FIB)-SEM, after Jun et al. [25]. These were square cross-section pillars $2 \mu \mathrm{m}$ in width with height to width ratios of 1.9-2.6:1 [25]. The FIB micropillars were compressed in situ at a strain rate of $10^{-3} \mathrm{~s}^{-1}$ using an Alemnis nanoindenter in displacement control with a $10 \mu \mathrm{m}$ diameter diamond punch tip in a FEI Quanta SEM.

After ageing $\left(750^{\circ} \mathrm{C} / 80 \mathrm{~h}\right), 29 \pm 2 \%$ area fraction of fine lamellar precipitates could be observed with a width of $\sim 40 \mathrm{~nm}(41 \pm 14 \mathrm{~nm}, n=20)$, spaced $70 \mathrm{~nm}$ apart $(68 \pm 20 \mathrm{~nm}, n=30)$, Figure 1a. The lamellae had darker backscattered electron (BSE) contrast when compared to the surrounding matrix, indicating a lower average $\mathrm{Z}$. The XRD pattern collected from the alloy in the solution heat treated condition was found to contain A2 reflections with a lattice parameter of $3.14 \pm 0.01 \AA$ (see Figure $1 \mathrm{~b}$ ), with an additional peak noted at $42.5^{\circ}$. In the aged condition, reflections were observed from an A2 phase as well as a B2 phase, with lattice parameters of $3.18 \pm 0.01 \AA$ and $2.98 \pm 0.01 \AA$ respectively. These represented a misfit $\delta a=-6.1 \%$, where $\delta a=\left(a_{\text {precipitate }}-a_{\text {matrix }}\right) / a_{\text {matrix }}[3]$. In both conditions it was observed that each of the A2 reflections had shoulders at lower angles, which is indicative of the presence of $\omega$ phase [16]. In the aged alloy, the sole $42.5^{\circ}$ peak in the solution heat treated condition may have been related to a low volume fraction of $\mathrm{B} 2$ or a reflection from the $\omega$ phase. TEM was employed to investigate further.

In the solution heat treated condition, bright field TEM and scanning TEM (STEM) imaging found no secondary features larger than $5 \mathrm{~nm}$. Selected area diffraction pat-
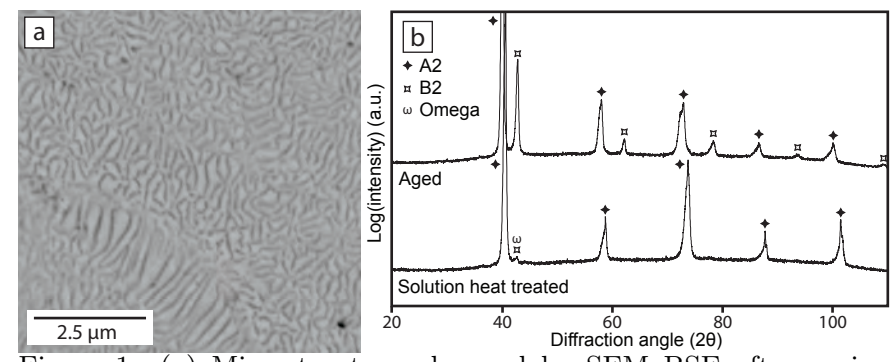

Figure 1: (a) Microstructure observed by SEM BSE after ageing at $750^{\circ} \mathrm{C}$ for $80 \mathrm{~h}$. (b) X-ray diffraction patterns obtained in the solution heat treated and aged condition $(\mathrm{Cu} \mathrm{K} \alpha)$.

terns (SADPs) (with a $200 \mathrm{~nm}$ aperture) from a sample in the solution heated condition identified $\mathrm{A} 2$ reflections, Figure 2a. Additional reflections consistent with incommensurate $\omega$ phase were observed, as previously reported in Ti-Fe alloys and Ti-Fe-Mo alloys $[12,16]$. No B2 reflections were observed, indicating that the $42.5^{\circ}$ peak observed in XRD (Figure 1b) was due to $\omega$. However, B2 may have been sampled by XRD owing to macrosegregation, but not present in the small areas examined by TEM. Previous work on similar alloys has identified that $\omega$ occurs as $\sim 1 \mathrm{~nm}$ domains formed on cooling [16]. SADPs (200 nm aperture) collected in the aged condition are shown in Figure 2b, with the A2 and B2 reflections identified, the $\mathrm{B} 2$ reflections corresponding to a smaller lattice parameter than the A2. An orientation relationship of $<100>_{\mathrm{A} 2} / /<100>_{\mathrm{B} 2},\{100\}_{\mathrm{A} 2} / /\{100\}_{\mathrm{B} 2}$ was found. However, the axes of the B2 lamellae were not found to relate to fixed crystallographic directions. This suggests that the nucleation of the B2 precipitates is orientation dependent, but that their growth is not orientation confined. The microstructure and orientation relationship were suggestive of a (pseudo)spinodal decomposition or discontinuous precipitation. However, study of interrupted heat treatments would be required to confirm the formation reaction. The multiplicity of the higher order spots was due to double diffraction from the lamellae and matrix channels being of similar width to the foil thickness [26] (see Figure 2 in [21]) as well as some foil bending. From the diffraction spots a misfit of $-6.1 \%$ was found. Adjustment of the exposure time and contrast, Figure 2c, identified additional diffuse reflections from the incommensurate $\omega$ phase. The lower intensity of the $\omega$ reflections when compared to the solution heat treated condition suggested that the aged condition may have a lower volume fraction of $\omega$ [27]. The streaking of the $\omega$ reflections indicates a structure change between the conditions, which may also influence their intensity [27].

High-angle annular dark-field (HAADF)-STEM imaging in the aged condition, Figure 1d, indicated that the B2 precipitates had similar Ti content but were enriched in Fe and contained minimal Mo, Figures 1e and f. This was consistent with near equilibrium compositions at $750{ }^{\circ} \mathrm{C}$ of $(62.8 \pm 0.6) \mathrm{Ti}-(6.4 \pm 0.4) \mathrm{Fe}-(30.8 \pm 1.0) \mathrm{Mo}$ (at.\%) for $\mathrm{A} 2$ $(\mathrm{Ti}, \mathrm{Fe})$ and $(52.4 \pm 0.6) \mathrm{Ti}-(44.6 \pm 1) \mathrm{Fe}-(2.9 \pm 1.0) \mathrm{Mo}$ 
for $\mathrm{B} 2 \mathrm{TiFe}[20]$. The reduction in Fe and enrichment in Mo of the bcc (A2) matrix could be expected to lower the propensity for $\omega$ formation [13, 27], as observed.

The alloy microhardness was found to be $\mathrm{HV}_{0.5}=5.8 \pm$ $0.1 \mathrm{GPa}$ in the solution heat treated condition, and $6.4 \pm$ $0.2 \mathrm{GPa}$ after aging. Cracking was not observed at the indent corners, as in brittle materials [28]. Macroscopic compression testing found that the homogenised alloy had a yield strength of $\sigma_{y, 0.2}=1335 \pm 85 \mathrm{MPa}$, which increased to $1890 \pm 80 \mathrm{MPa}$ upon ageing (see Figure 3 in [21]). In both conditions some plasticity was observed, but only minimal $(<2 \%)$ ductility.

In both conditions the presence of $\omega$ can be expected to contribute to the hardness and to the lack of ductility [13]. The pronounced increase in the microhardness and strength on aging was anticipated due to the introduction of the B2 TiFe precipitates. The strength of the aged alloy is higher than that of A2-B2 Ti-TiFe binary eutectic alloys that have compressive yield strengths of $1538 \mathrm{MPa}[7,29]$ and up to $1800 \mathrm{MPa}$ in ternaries [8, 9],
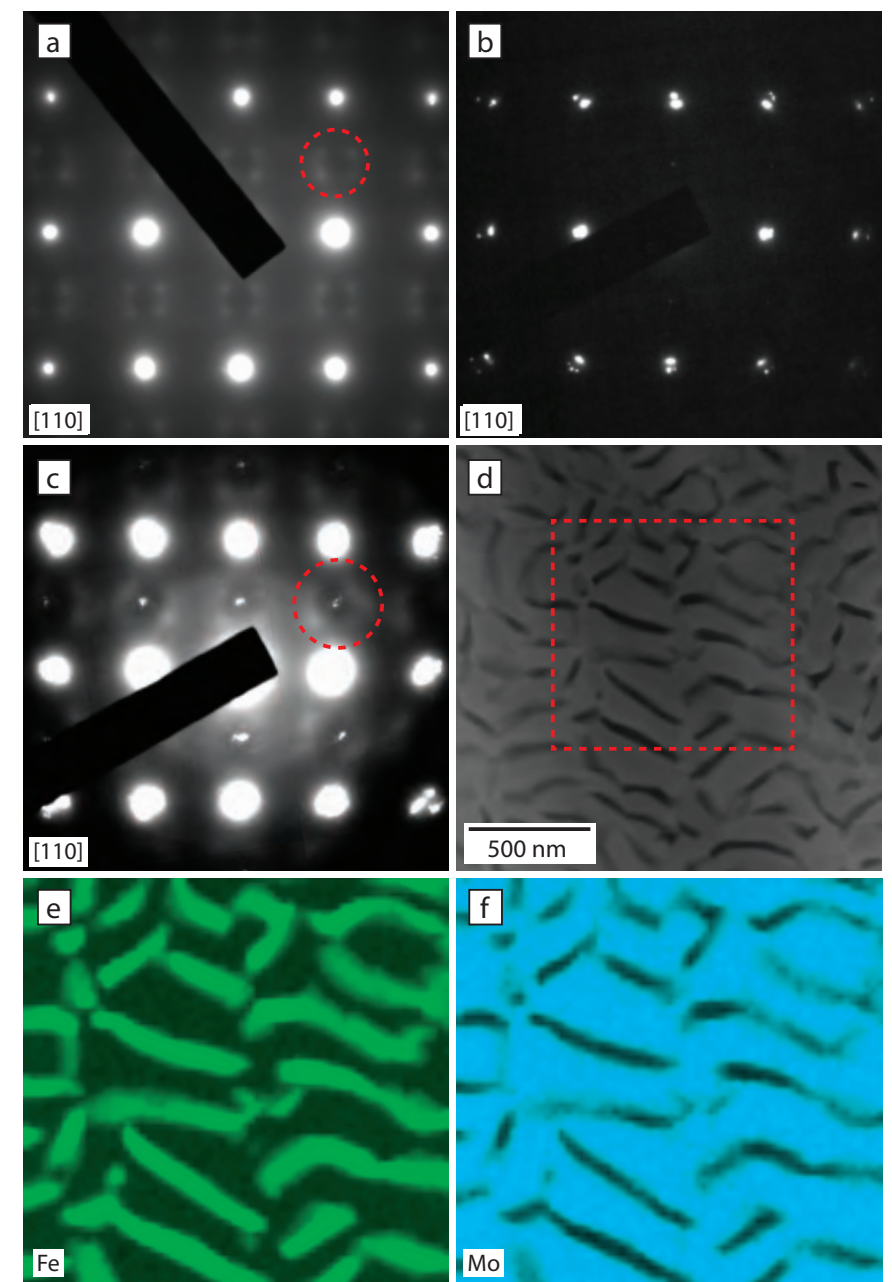

Figure 2: TEM SADPs from the alloy in (a) the solution heat treat condition, (b) the aged condition showing A2 and B2 reflections with (c) having increased exposure to reveal the omega reflections and B2 superlattice reflections. Aged alloy (c) HAADF-STEM micrograph as well as EDX elemental maps for (e) Fe, and (f) Mo. with similar ductility. Ti-Fe-Sn A2-B2 eutectic alloys [7, 8] and $\mathrm{Ti}-\mathrm{Fe}-\mathrm{Nb}$ alloys [9] exhibit higher ductilities than binary Ti-Fe eutectic alloys, owing partly to a refined microstructure but also due to the presence of primary $\beta$ (A2) dendrites. However, these eutectic alloys require cooling rates of around $10 \mathrm{~K} \mathrm{~s}^{-1}$ [29] that may be unsuitable for larger castings, while the lack of a single-phase field means they cannot readily be thermo-mechanically processed.

Micropillar compression testing was employed to probe the precipitate strengthening contribution, in a condition where ductility would be observed and similarly-oriented single crystals could be examined, avoiding the effect of grain size. From an EBSD map of the solution heat treated alloy a grain was identified with Euler angles $\left(\phi_{1}=120.0\right.$, $\left.\Phi=39.4, \phi_{2}=275.6^{\circ}\right)$ that were similar to a grain in the aged condition with $\left(\phi_{1}=122.0, \Phi=42.7, \phi_{2}=280.8^{\circ}\right)$. FIB milling was used to produce sets of $2 \mu \mathrm{m}$ square pillars [25] in each condition, Figure 3. In the solution heat treated condition the average $0.2 \%$ proof stress was $2.2 \mathrm{GPa}$, while in the aged condition it was $2.8 \mathrm{GPa}$, a similar increase to that observed in macroscopic testing. The greater overall strength observed is consistent with the size effect commonly observed in the micropillar testing of bcc materials [30]; indications of dislocation starvation such as popins were not observed.

In situ imaging of the pillar faces indicated that in the solution heat treated condition the alloy tended to deform with clear slip traces across the pillars, Figure 3. In contrast, in the aged condition the pillars tended to bulge with a slip trace visible only at higher strains than were seen in the solution heat treated condition, with the slip traces at the final $10 \%$ strain less clearly defined and the pillars more visibly bulged (for videos see Supplementary material in [21]). This behaviour suggested that the precipitates could not be easily cut by dislocations. The slip systems with the highest Schmid factors for the solution heat treated pillar were $(\overline{1} 32)[11 \overline{1}]=0.489,(\overline{1} 21)[11 \overline{1}]=0.484$, and $(011)[11 \overline{1}]=0.374$, which were similar to those in the aged condition of $(\overline{1} 32)[11 \overline{1}]=0.495,(\overline{1} 21)[11 \overline{1}]=0.497$ and $(011)[11 \overline{1}]=0.366$ (see Table 2 in $[21]$, method after [25]). Therefore, the $(\overline{1} 21)[11 \overline{1}]$ and $(\overline{1} 32)[11 \overline{1}]$ slip systems had very similar Schmid factors, which were markedly higher than for (011)[11̄] slip. The slip traces observed on each of the faces [31] indicated that slip on $\{132\}$ was active in both microstructural conditions, most likely with a $<111>$ Burgers vector. On the 'front' face of each pillar the slip trace was not linear, indicating activity on two slip systems. The continuity of the trace on this face of the pillars implied that the step was formed due to cross-slip of screw dislocations on two slip planes. Analysis of the edges of this band indicated that the trace could be formed from a combination of the primary $(\overline{1} 32)[11 \overline{1}]$ slip system as well as secondary $(\overline{1} 21)[11 \overline{1}]$ slip.

To further investigate the deformation behaviour of the A2-B2 aged alloy, deformed samples were studied by TEM. An electropolished sample prepared from a $3 \mathrm{~mm}$ compression tested sample macroscopically loaded to the $0.2 \%$ 

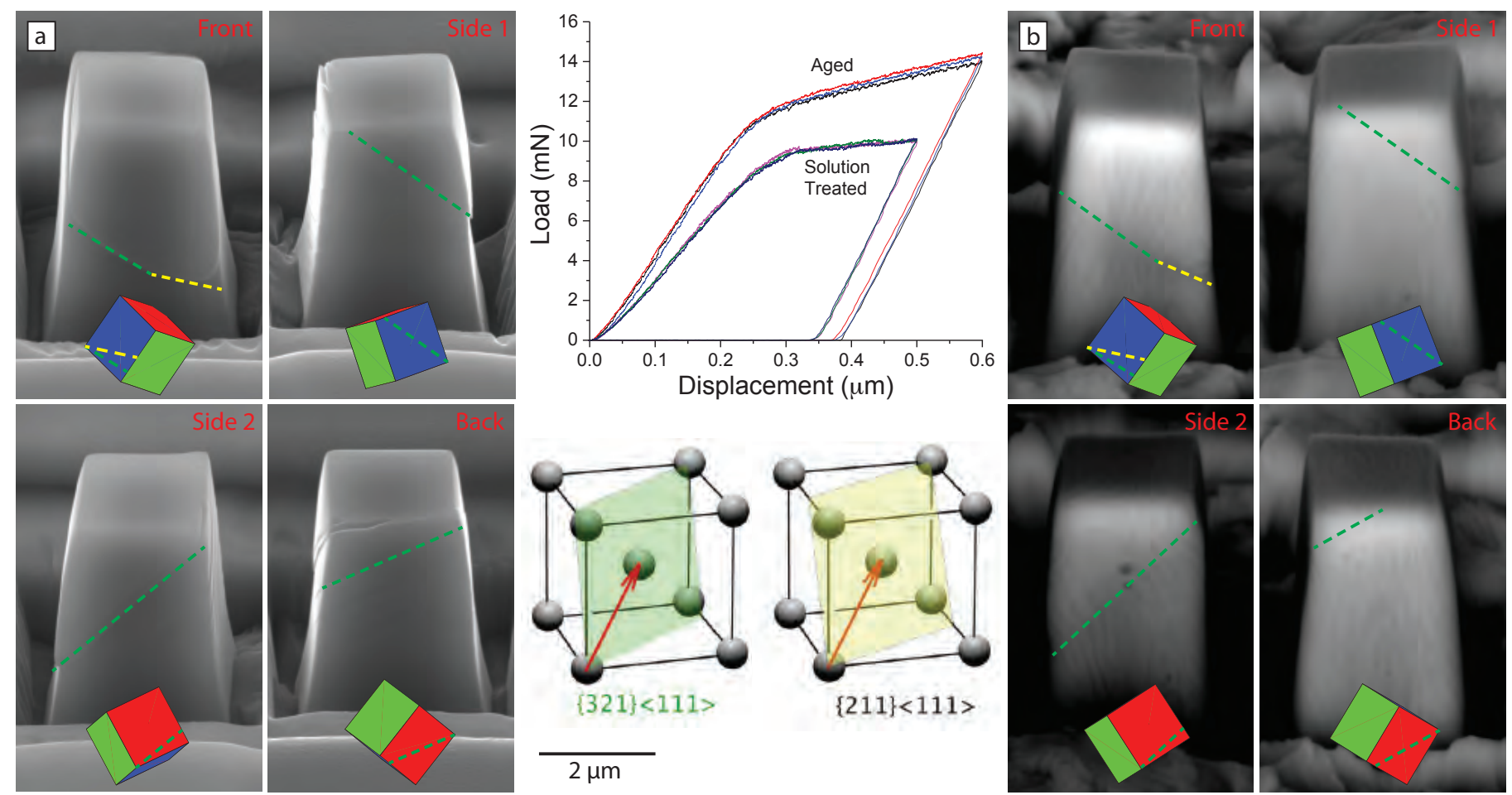

Figure 3: Micropillar compression testing of (a) the solution heat treated condition and (b) the aged condition, showing the post-deformation pillar faces, slip traces and load displacement curves to $10 \%$ strain as well as the slip systems identified

proof stress is compared to a FIB-milled sample from the micropillar deformed to $10 \%$ strain in Figure 4. Within the sample deformed to a small strain, single dislocations were observed in the bcc A2 matrix channels. At the A2B2 boundaries thickness fringes were observed, owing to the interface being inclined in the foil. In addition, bend contours were seen from top to bottom across the A2 domains. Vanishingly few dislocations were observed within the $\mathrm{B} 2$ precipitates at various tilts and no dislocations were observed crossing the precipitates, suggesting that the precipitates were not sheared. Regions of the foil were also observed to contain fine A2 subgrains $\sim 200 \mathrm{~nm}$ in diameter with $\sim 3^{\circ}$ misorientation in addition to the B2 lamellae, Figure $4 \mathrm{~b}$. These are surmised to have formed as a consequence of the recovery of the misfit dislocations induced during the precipitation of the B2 phase, and would be an additional source of strengthening of the material. Using EBSD, partial recrystallisation was also observed as a consequence of the aging heat treatment.

In the foil removed from the aged micropillar [32, 33], a clear slip trace was not observed, Figure 4c. Bright field imaging and tilting to suitable diffraction conditions revealed a network of dislocations within the matrix interacting with a B2 precipitate, Figure 4d. The dislocations were unable to cut through the $\mathrm{B} 2$ precipitate to the $\mathrm{A} 2$ matrix on the other side. This blocking of dislocations is consistent with the pronounced precipitation strengthening in the alloy as well as the pillar bulging observed due to the difficulty of slip on a single plane.

In summary, a bcc $\beta$ Ti-Fe-Mo alloy has been developed that is strengthened by ordered $\mathrm{B} 2 \mathrm{TiFe}$ precipitates produced by ageing from a single-phase solid solution. The precipitates were lamellar with width of $\sim 40 \mathrm{~nm}$, interlamellar spacing of $\sim 70 \mathrm{~nm}$, an orientation relationship of $<100>_{\mathrm{A} 2} / /<100>_{\mathrm{B} 2},\{100\}_{\mathrm{A} 2} / /\{100\}_{\mathrm{B} 2}$ and misfit of $-6.1 \%$. An apparent lowering of the $\omega$ volume fraction in the matrix in the aged condition compared to the solution heat treated condition was attributed to the lower
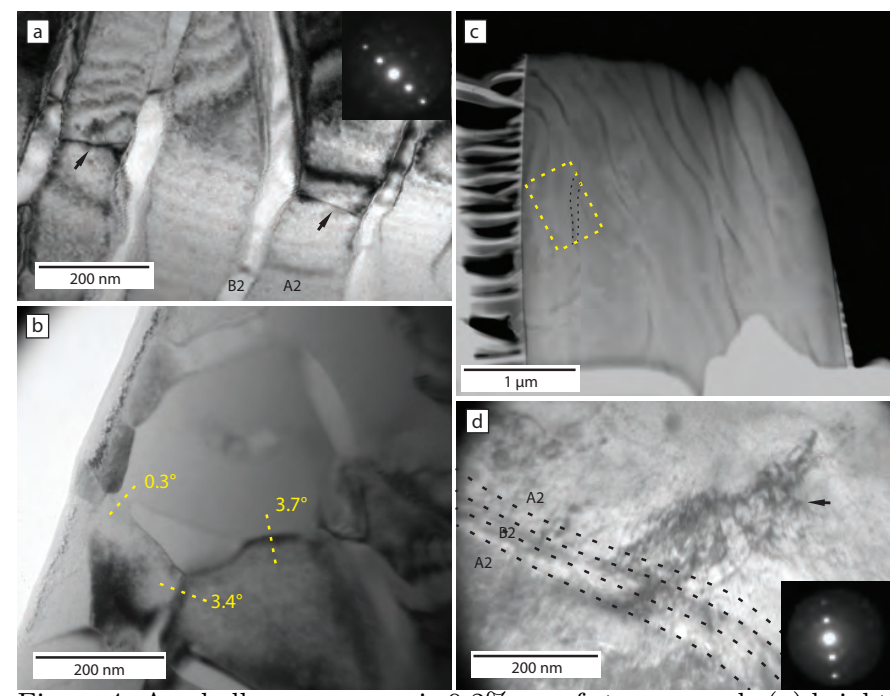

Figure 4: Aged alloy macroscopic $0.2 \%$ proof stress sample (a) bright field of A2 dislocations (arrows), SADP inset, (b) multiple A2 subgrains with misorientations from SADPs identified. Aged alloy micropillar sample (c) HAADF-STEM of the FIB lamellae, indicating the area analysed in (d) a bright field image of dislocations blocked by a $\mathrm{B} 2$ precipitate, SADP inset. 
Fe and higher Mo content of the matrix. The aged alloy had a compressive proof stress of $1.9 \mathrm{GPa}$ and $4.9 \%$ strain to failure, with a density of $6.68 \mathrm{~g} \mathrm{~cm}^{-3}$. Shearing of the precipitates by dislocations was not observed using TEM, with deformation being confined to the matrix phase. In both macroscopic and micropillar testing, ageing produced an increase in the proof strength of over $550 \mathrm{MPa}$.

\section{Acknowledgements}

G Zheng and R Sweeney assisted with the X-ray diffraction and KM Rahman with the compression testing. This work was supported by EPSRC (EP/N509486/1, EP/H022309/1, $\mathrm{EP} / \mathrm{H} 500375 / 1$, EP/M005607/1 and EP/L025213/1). T.B. Britton acknowledges funding from RAEng for his research fellowship.

[1] M.J. Donachie and S.J. Donachie, Superalloys: A Technical Guide, ASM Int., 2nd ed., 2002.

[2] R. Reed, The superalloys: fundamentals and applications, CUP, 2006.

[3] G. Ghosh and G.B. Olson, Acta Mater. 55 (2007) 3281-3303.

[4] S. Naka and T. Khan, J. Phase Equil. 18(1997) 635-649.

[5] C.H. Liebscher, V. Radmilovic, U. Dahmen, M. Asta, and G. Ghosh, J. Mater. Sci. 48 (2012) 2067-2075.

[6] N.Q. Vo, C.H. Liebscher, M.J. S. Rawlings, M. Asta, and D. C. Dunand, Acta Mater. 71 (2014) 89-99.

[7] J. Das, K.B. Kim, F. Baier, W. Löser, A. Gebert, and J. Eckert, J. Alloys Compd. 434-435 (2007) 28-31.

[8] D.V. Louzguine-Luzgin, L.V. Louzguina-Luzgina, H. Kato, and A. Inoue, Acta Mater. 53 (2005) 2009-2017.

[9] G.H. Cao, Y.F. Peng, N. Liu, X. Li, Z. S. Lei, Z.M. Ren, D. Gerthsen, and A.M. Russell, Mater. Sci. Eng. A 609 (2014) 60-64.

[10] J. L. Murray, Bul. Alloy Phase Diag. 2 (1981) 320-334.

[11] R.J. Van Thyne, H.D. Kessler, and M. Hansen, Trans. Am. Soc. Metals 44 (1952) 974-989.

[12] G.I. Nosova, N.B. D'yakonova, and I.V. Lyasotskii, Met. Sci. Heat Treat. 48 (2006) 427-432.

[13] S.K. Sikka, Y.K. Vohra, and R. Chidambaram, Prog. Mat. Sci. 27 (1982) 245-310.

[14] G. Lütjering and J.C. Williams, Titanium, Springer Sci. \& Bus. Media, 2007.

[15] W.E. Collings, J.C. Ho, and R.I. Jaffee, Phy. Rev. B 5 (1972) $4435-4449$.

[16] A.J. Knowles, N.G. Jones, O.M.D.M Messé, J.S. Barnard, C.N. Jones, and H.J. Stone, Int. J. Refract. Met. Hard Mater. 60 (2016) $160-168$.

[17] Z.P. Jin and C. Qiu, Metall. Trans. A 24 (1993) 2137-2144.

[18] A. Watson, T. Markus, Ternary Steel Systems, Springer Berlin, 2015.

[19] A.J. Knowles, N.G. Jones, C.N. Jones, and H.J. Stone, Proc. 13th World Conf. Titanium (2016) 1231-1236.

[20] A.J. Knowles, N.G. Jones, C.N. Jones, and H.J. Stone, Metall. Mater. Trans. A in press.

[21] A.J. Knowles, T.S. Jun, A. Bhowmik, N.G. Jones, T.B. Britton, F. Giuliani, H.J Stone, D. Dye, Data in Brief submitted

[22] Standard Test Methods for Determining Average Grain Size E 112, ASTM Int., 2014.

[23] Standard Test Methods of Compression Testing of Metallic Materials at Room Temperature E 9 - 89a, ASTM Int., 2000.

[24] A. Bhowmik, S. Neumeier, J.S. Barnard, C.H. Zenk, M. Goken, C.M.F. Rae, and H.J. Stone, Phil. Mag. 94 (2014) 3819-2944.

[25] T.S. Jun, G. Sernicola, F. Dunne, and T.B. Britton, Mat. Sci. Eng. A 649 (2016) 39-47.

[26] D.B. Williams and C.B. Carter, Transmission Electron Microscopy, Springer US, 2009.

[27] W. Sinkler and D.E. Luzzi, Acta Metall. 42 (1994) 1249-1260.

[28] A. Bhowmik, C.N. Jones, I.M. Edmonds, and H.J. Stone, J. Alloys Compd. 530 (2012) 169-177.
[29] D.V. Louzguine, H. Kato, and A. Inoue, J. Alloys Compd. 384 (2004) L1-L3.

[30] J.R. Greer and J.Th.M.De Hosson, Prog. Mater Sci. 56 (2011) 654-724.

[31] T.S. Jun, Z. Zhang, G. Sernicola, F. Dunne, and T.B. Britton, Acta Mater. 107 (2016) 298-309.

[32] H.E. Weekes, V.A. Vorontsov, I.P. Dolbnya, J.D. Plummer, F. Giuliani, T.B. Britton, and D. Dye, Acta Mater. 92 (2015) 81-96.

[33] A. Bhowmik, I.P. Dolbnya, T.B. Britton, N.G. Jones, G. Sernicola, C. Walter, P. Gille, D. Dye, W.J. Clegg, and F. Giuliani, Appl. Phys. Lett. 108 (2016) 1-5. 